\title{
Speech-language therapy stimulation in children with Down's syndrome
}

\author{
Mariane Sousa Regis ${ }^{(1)}$ \\ Ivonaldo Leidson Barbosa Lima ${ }^{(1)}$ \\ Larissa Nadjara Alves Almeida ${ }^{(1)}$ \\ Giorvan Ânderson dos Santos Alves ${ }^{(1)}$ \\ Isabelle Cahino Delgado(1)
}

(1) Universidade Federal da Paraíba - UFPB, João Pessoa, Paraíba, Brasil.

Research support source: Scientific Initiation by the National Council for Scientific and Technological Development (CNPq); Master's Scholarships from the Brazilian Federal Agency for the Support and Evaluation of Graduate Education - (Capes).

Conflict of interests: Nonexistent

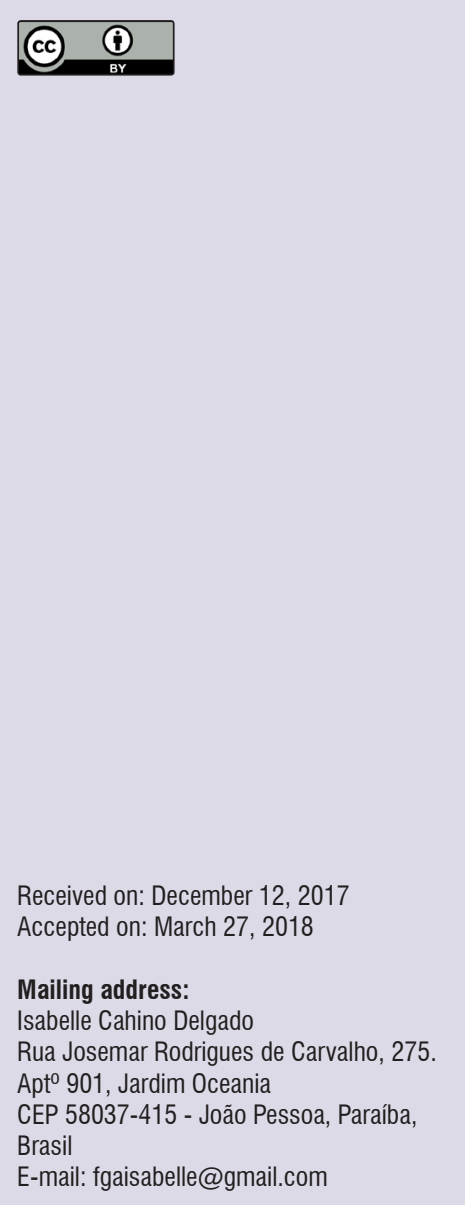

\section{ABSTRACT}

Objective: to analyze the contributions of speech-language therapy to the language development of children with Down syndrome (DS).

Methods: eleven children with DS participated in the research. The children were between zero and five years of age, of both genders and attending a university extension project involving eight therapy sessions following stimulation guidelines. Children were evaluated before and after speech-language stimulation. The stimulation guidelines were based on the following aspects of language development: coordination of sensorimotor schema, constitution of object permanence, gestural/body imitation, imitation of utterances, deferred imitation and use of symbolic schema, communicative intent, receptive vocabulary and expressive vocabulary: words and phrases. The study was approved by the Research Ethics Committee of the institution. Data were analyzed quantitatively.

Results: there were significant differences in the pre- and post-speech-language intervention in the following skills parameters: gestural/body imitation, imitation of utterances, deferred imitation and use of symbolic schema, communicative intent and receptive vocabulary.

Conclusion: early stimulation of linguistic and cognitive aspects is important in the development of children with DS, as evidenced by the immediate development of speech-language skills in children after the intervention.

Keywords: Speech-language; Down syndrome; Language; Rehabilitation of Speech and Language Disorders 


\section{INTRODUCTION}

Down syndrome (DS) is a genetic alteration of chromosome 21. It is the most common syndrome in the world and can be observed in different regions and races and among different socioeconomic levels. This chromosomal disorder affects the development a person's motor, cognitive, language, self-care and socialization skills ${ }^{1}$.

In terms of language in this population, especially when compared with typically developing (TD) children, the expressive area develops later than and out of phase with the receptive area and symbolic function ${ }^{2,3}$. Furthermore, the lexical, receptive and expressive performance of children with DS is lower than that of children with TD, even when matched for mental age'.

The development of oral language involves a complex series of cognitive, perceptual and language skills that start to form in the preverbal period. Symbolic construction is a cognitive ability that is essential to linguistic sign formation and, consequently, to the use of words as a form of expression. Therefore, the development of symbolism is directly related to oral language $\mathrm{e}^{4,5}$.

DS causes a deficit in language development, but even with this difficulty, a person with the syndrome can use language and to develop it if this process is stimulated effectively by family members and by a multidisciplinary team, particularly by a speech-language therapist.

The symbolism and cognition of children with DS serve as a basis for the development of representation skills, which are related to the emergence of oral language. This language modality is of fundamental importance to the subject's development and is the starting point for future language acquisition, such as reading and writing.

To encourage the development of cognition and language, interventions are needed at every life stage of a person with DS and must be developed according to each individual's characteristics.

Speech-language interventions oriented toward language development in DS have a unique importance because earlier intervention results in greater stimulation of the subject's brain plasticity. This term includes an adaptive skill/ability to modify the structural and functional organization of the central nervous system, which is affected by the quality, duration and form of stimulation that the individual receives so that he/she can develop ${ }^{6}$.
Brain plasticity can help promote language development in children with DS; moreover, the therapeutic process is more promising when these children receive intervention as early as possible. Therefore, studies are needed to examine the language development process in this population of children to provide insights into speech-language therapy in terms of the development and selection of resources and strategies that aid in the complex journey of language acquisition ${ }^{2}$.

Thus, speech-language therapy that is appropriate for language development in children with DS would help reduce further losses, contribute to their overall development and could offer them a better quality of life and increased interaction with the environment as well as stimulate his/her learning, providing greater independence, within their limitations, along with better social performance and the development of reading and writing.

Therefore, the goal of this study is to analyze the contributions of speech-language therapy to language development in children with DS.

\section{METHODS}

All ethical considerations were preserved during this research, and this study was approved by the Ethics Committee for Research with Human Beings of the home institution under approval number 0386/15 and CAAE No. 46076215.8.0000.5188. The protocol respected all provisions of Resolution \#466/2012 of the National Health Council relating to ethics in research involving human subjects.

The research was conducted at the SpeechLanguage Clinic-School of the home institution under the auspices of the extension project "Literacy at Stake: Speech-language interventions in subjects with Down syndrome." The research was descriptive, experimental and longitudinal in nature.

Forty-nine individuals with DS, aged between zero and 33 years old, were included in the extension project. The eligibility criteria for participation in the study were as follows: child with DS, of either gender, aged between zero and five years old, with no other syndromes or associated hearing loss, regularly attending the extension project and whose guardians had given their consent to participate in all study procedures. Eleven children with DS met the eligibility criteria and participated in the research.

Data collection began after interviewing the children's parents and explaining the research objectives and procedures. After signing the terms of free 
and informed consent, the subject's initial evaluation was conducted, based on the application of an evaluation plan for the early development of language and cognition in DS. This plan had been developed for use in the extension project by means of an analysis of treatment plans for this population ${ }^{7}$ (Appendix A).

The evaluation plan had eight points of inquiry: 1 . Coordination of sensorimotor schemas, 2. Constitution of object permanence, 3. Gestural/body imitation, 4. Imitation of utterances, 5. Deferred imitation and use of symbolic schema, 6 . Communicative intent, 7. Receptive vocabulary and 8 . Expressive vocabulary: words and phrases. The researchers evaluated the children at each point of the plan and kept a record of the participants' responses as follows: unsatisfactory $(U)$, the child did not perform the proposed activity; regular $(\mathrm{R})$, the child performed the activity partially or performed the whole activity with the therapist's help; or satisfactory (S), the child performed all activity autonomously, without the therapist's help.

The evaluation plan points then served as clinical guidelines for the speech-language process that was applied to the research participants. The guidelines contained specific evidence for the researched group, and each was applied in one therapy session (Figure 1).

\begin{tabular}{|c|c|}
\hline GUIDELINES & SUGGESTED ACTIVITIES \\
\hline $\begin{array}{l}\text { 1. Coordination of } \\
\text { sensorimotor schemas }\end{array}$ & $\begin{array}{l}\text { aying building games; using play dough with equal and different forms; using wood blocks; touching parts of her own } \\
\text { dy (arm, fingers, thigh, leg, ankle) with and without music; engaging with toys that help them discover their body } \\
\text { id distinguish different textures, shapes and colors (rattles, musical toys, cloth or plastic booklets, balls with different } \\
\text { xtures to be grabbed with both hands); viewing photo albums with illustrations of known objects, e.g., toy phone. }\end{array}$ \\
\hline $\begin{array}{l}\text { 2. Constitution of object } \\
\text { permanence }\end{array}$ & $\begin{array}{l}\text { Hide-and-seek games; hidden object games; verbal object permanence games (talking about people when they are not } \\
\text { present, such as "Mom's out there." This practice encourages him/her to understand that people continue to exist even } \\
\text { when they are not there; toys/games of cause and effect. }\end{array}$ \\
\hline 3. Gestural/body imitation & $\begin{array}{l}\text { lowing kisses with body movement; answering the phone; using gestures in songs that address body image (yellow } \\
\text { hick, dancing fingers, little ant, for example); puppet theater. }\end{array}$ \\
\hline 4. Imitation of utterances & $\begin{array}{l}\text { Imitating their utterances to provide the stimulating feedback, thus imitating them back; assigning meaning to the child's } \\
\text { utterances (if he/she says "woof woof" for all animals or "mom" at random, their meaning can be assigned respectively); } \\
\text { imitating sounds of objects (car = vroom beep beep/putting doll to sleep = lull-a-baby/etc.). Examples: let's play farm, } \\
\text { in which the patient imitates the therapist, orally repeating the onomatopoeia of the respective animal or telling a well } \\
\text { dramatized history, in which the patient repeat sounds that are made in the story; tip for anyone who is working with } \\
\text { animals: application of BABY ANIMAL SOUNDS. }\end{array}$ \\
\hline $\begin{array}{l}\text { 5. Deferred imitation and } \\
\text { use of symbolic schema }\end{array}$ & ause the patient to imitate their symbolic schema models, with music or objects. \\
\hline 6. Communicative intent & $\begin{array}{l}\text { Clap along to a song, cause the patient to become involved with the situation and, from there, the therapist should stop the } \\
\text { action and wait for the child to take the initiative to make it continue; play pass the ball, for example, and, out of nowhere, } \\
\text { stop and wait for the child to signal her intention for the activity to continue. }\end{array}$ \\
\hline 7. Receptive vocabulary & $\begin{array}{l}\text { Giving meanings to the objects (their respective functions); preventing the diminutive. Correctly naming objects ("woof } \\
\text { woof" for dog and "meow" for = cat); avoiding diminutives; during games or symbolic play, naming objects and asking } \\
\text { the child to choose between the ball or the push chair (or others) and based on the child's choice, reinforcing the object's } \\
\text { name; working with the most common semantic fields (showing function, shape, color, tactile sensation, etc.). }\end{array}$ \\
\hline $\begin{array}{l}\text { 8. Expressive vocabulary: } \\
\text { words and phrases }\end{array}$ & $\begin{array}{l}\text { Creating make-believe situations involving specific characteristics of animals or objects (where found, physical } \\
\text { characteristics); request that the child; cause the patient to feel the need to use oral language to communicate. Play } \\
\text { games (bowling, for example), associating them with "one, two, three, go!", stimulating the patient to reproduce them. }\end{array}$ \\
\hline
\end{tabular}

Figure 1. Speech-language stimulation guidelines in Down syndrome 
The guidelines were applied to the children with DS by two therapists who worked on the extension project and who were Speech-Language Therapy undergraduates at the home institution, trained by the study researchers and given a prior schedule of the goals to be achieved in the therapeutic sessions.

Student training occurred over the course of eight meetings as the research was being conducted. In this training, the researchers presented the objectives and procedures for each session, performed simulations and engaged in theoretical and case discussions for each stimulation guideline.

After each child's eight-week intervention, comprising one appointment every week, the evaluation plan was reapplied to verify the effectiveness of the therapeutic interventions in order to investigate the benefits of speech-language therapy for the development of children with DS. It should be emphasized that the parents were not involved in the evaluation sessions, guideline application or reevaluation. The extensions provided information about the procedures performed, and the guardians were given guidelines after the treatments.

Finally, the before and after speech-language therapy responses in each plan were evaluated. The study variables included the items investigated by the evaluation plan and stimulated by the intervention guidelines. These variables were described numerically and systematized for data analysis (Figure 2).

\begin{tabular}{|c|c|}
\hline GUIDELINES & $\begin{array}{l}\text { TESTS/STUDY VARIABLES } \\
\end{array}$ \\
\hline \multirow{2}{*}{$\begin{array}{l}\text { 1. Coordination of } \\
\text { sensorimotor schemas }\end{array}$} & T1- Incentive to pick up and handle/knead and squeeze the offered objects. \\
\hline & T2- Incentive to pick up and handle/put together and stack the objects offered. \\
\hline \multirow[b]{2}{*}{$\begin{array}{l}\text { 2. Constitution of object } \\
\text { permanence }\end{array}$} & T3- Hide an object of interest to the patient, leaving a part showing, so he/she can find it. \\
\hline & $\begin{array}{l}\text { T4- Hide the object in hand, without the patient seeing, put it in another location and encourage the } \\
\text { patient to find it. }\end{array}$ \\
\hline \multirow[b]{2}{*}{ 3. Gestural/body imitation } & T5- Make visible gestures to the patient, so that he/she then performs the same gesture. \\
\hline & $\begin{array}{l}\text { T6- Perform an action with an object in front of the patient and then offer the same object to him/her, } \\
\text { suggesting that he/she mimics the action. }\end{array}$ \\
\hline \multirow{4}{*}{ 4. Imitation of utterances } & T7- Associate a particular sequence of sounds to motor actions, so that the patient imitates them. \\
\hline & T8- Associate an action with its corresponding verbalization. \\
\hline & $\begin{array}{l}\text { T9- Produce a sound and then ask the patient to identify the source that produced it, with visual } \\
\text { support. }\end{array}$ \\
\hline & $\begin{array}{l}\text { T10- Produce a sound and then ask the patient to identify the source that produced it, without visual } \\
\text { support. }\end{array}$ \\
\hline \multirow{2}{*}{$\begin{array}{l}\text { 5. Deferred imitation and use } \\
\text { of symbolic schema }\end{array}$} & T11- Offer an object and verify that the patient performs the symbolic action of the chosen object. \\
\hline & $\begin{array}{l}\text { T12- Offer non-figurative objects so that the patient represents symbolic schemas in the absence of } \\
\text { the object, providing a model. }\end{array}$ \\
\hline \multirow[t]{2}{*}{ 6. Communicative intent } & $\begin{array}{l}\text { T13- Present a song, dancing with the patient, and then stop the game and wait for the child to } \\
\text { communicate in any way that she wants to play again. }\end{array}$ \\
\hline & T14- Play cooperative games with the child. \\
\hline \multirow[b]{2}{*}{ 7. Receptive vocabulary } & T15- Name two objects and ask the patient to choose one of the two objects, pointing to it. \\
\hline & $\begin{array}{l}\text { T16- Separate two or three objects and name them several times, without the use of gesture, and then } \\
\text { verbally ask the patient to point to, or fetch them, one by one. }\end{array}$ \\
\hline \multirow{3}{*}{$\begin{array}{l}\text { 8. Expressive vocabulary: } \\
\text { words and phrases }\end{array}$} & T17- Promote situations where the patient is asked to name 6 figures. \\
\hline & T18- Promote situations where the patient is asked to describe figures. \\
\hline & $\begin{array}{l}\text { T19- Sing songs while performing contextualized gestures with the patient; after singing it a few times, } \\
\text { leave gaps to be completed by the patient. }\end{array}$ \\
\hline
\end{tabular}

Figure 2. Study variables for each stimulation guideline 
The data were categorized and entered into a digital spreadsheet. Subsequently, the variables were analyzed descriptively and inferentially using the Wilcoxon test for related samples in order to compare the pre- and post-speech-language periods. R Statistical software version 2.11.0 was used, and a significance level of $5 \%$ was adopted.

Table 1. Results of pre- and post-speech-language stimulation

\begin{tabular}{|c|c|}
\hline Variable & p-value \\
\hline T1A x T1B & 0.180 \\
\hline T2A x T2B & 0.564 \\
\hline ТЗА $\times$ T3B & 0.257 \\
\hline $\mathrm{T} 4 \mathrm{~A} \times \mathrm{T} 4 \mathrm{~B}$ & 0.414 \\
\hline T5A $\times$ T5B & $0.038^{*}$ \\
\hline $\mathrm{T} 6 \mathrm{~A} \times \mathrm{T} 6 \mathrm{~B}$ & 0.157 \\
\hline T7A x T7B & $0.048^{*}$ \\
\hline T8A x T8B & 0.119 \\
\hline T9A x T9B & $0.048^{*}$ \\
\hline $\mathrm{T} 10 \mathrm{~A} \times \mathrm{T} 10 \mathrm{~B}$ & 0.608 \\
\hline $\mathrm{T} 11 \mathrm{~A} \times \mathrm{T} 11 \mathrm{~B}$ & $0.042^{*}$ \\
\hline $\mathrm{T} 12 \mathrm{~A} \times \mathrm{T} 12 \mathrm{~B}$ & $0.046^{*}$ \\
\hline $\mathrm{T} 13 \mathrm{~A} \times \mathrm{T} 13 \mathrm{~B}$ & $0.008^{*}$ \\
\hline $\mathrm{T} 14 \mathrm{~A} \times \mathrm{T14B}$ & 0.017 \\
\hline $\mathrm{T} 15 \mathrm{~A} \times \mathrm{T15B}$ & $0.048^{*}$ \\
\hline $\mathrm{T} 16 \mathrm{~A} \times \mathrm{T} 16 \mathrm{~B}$ & $0.021^{*}$ \\
\hline T17A x T17B & 0.317 \\
\hline T18A x T18B & 1.000 \\
\hline T19A x T19B & 0.257 \\
\hline
\end{tabular}

Legend: A = Pre-speech-language stimulation; B = Post-speech-language stimulation; $T$ = Test/Study variable (Figure 2)

Test: Wilcoxon; Significance level $p<0.05^{*}$ 
Based on the data in Table 1, the variables with significant differences were selected, and the results of the initial and final evaluations were determined (Table 2).

Table 2. Descriptive analysis of variables with significant difference before and after speech-language stimulation

\begin{tabular}{|c|c|c|c|c|c|}
\hline \multirow{3}{*}{ VARIABLES } & \multirow{3}{*}{ RESPONSES } & \multicolumn{4}{|c|}{ SPEECH-LANGUAGE EVALUATION } \\
\hline & & \multicolumn{2}{|c|}{ PRE-INTERVENTION } & \multicolumn{2}{|c|}{ POST-INTERVENTION } \\
\hline & & $\mathbf{N}$ & $\%$ & $\mathbf{N}$ & $\%$ \\
\hline \multirow{3}{*}{ T5 } & Unsatisfactory & 1 & 9.1 & 0 & 0 \\
\hline & Regular & 4 & 36.4 & 0 & 0 \\
\hline & Satisfactory & 6 & 54.5 & 11 & 100 \\
\hline \multirow{3}{*}{$\mathrm{T} 7$} & Unsatisfactory & 3 & 27.3 & 2 & 18.2 \\
\hline & Regular & 5 & 45.5 & 4 & 36.4 \\
\hline & Satisfactory & 3 & 27.3 & 5 & 45.5 \\
\hline \multirow{3}{*}{ T9 } & Unsatisfactory & 6 & 54.5 & 2 & 18.2 \\
\hline & Regular & 2 & 18.2 & 4 & 36.4 \\
\hline & Satisfactory & 3 & 27.3 & 5 & 45.5 \\
\hline \multirow{3}{*}{$\mathrm{T} 11$} & Unsatisfactory & 4 & 36.4 & 1 & 9.1 \\
\hline & Regular & 2 & 18.2 & 0 & 0.0 \\
\hline & Satisfactory & 5 & 45.5 & 10 & 90.9 \\
\hline \multirow{3}{*}{ T12 } & Unsatisfactory & 4 & 36.4 & 1 & 9.1 \\
\hline & Regular & 3 & 27.3 & 1 & 9.1 \\
\hline & Satisfactory & 4 & 36.4 & 9 & 81.8 \\
\hline \multirow{3}{*}{$\mathrm{T} 13$} & Unsatisfactory & 3 & 27.3 & 3 & 27.3 \\
\hline & Regular & 4 & 36.4 & 0 & 0.0 \\
\hline & Satisfactory & 4 & 36.4 & 8 & 72.7 \\
\hline \multirow{3}{*}{ T15 } & Unsatisfactory & 6 & 54.5 & 2 & 18.2 \\
\hline & Regular & 1 & 9.1 & 2 & 18.2 \\
\hline & Satisfactory & 4 & 36.4 & 7 & 63.6 \\
\hline \multirow{3}{*}{ T16 } & Unsatisfactory & 6 & 54.5 & 2 & 18.2 \\
\hline & Regular & 1 & 9.1 & 2 & 18.2 \\
\hline & Satisfactory & 4 & 36.4 & 7 & 63.6 \\
\hline
\end{tabular}

Legend: $\mathrm{T}=$ Test/Study variable (Figure 2))

\section{DISCUSSION}

Changes between pre- and post-speech-language stimulation were observed in the tests that analyzed gestural/body imitation (T5), imitation of utterances (T7 and T9), deferred imitation and the use of symbolic schema (T11 and T12), communicative intent (T13) and receptive vocabulary (T15 and $\mathrm{T} 16)$.

The literature confirms that imitation is very important for the development of socialization, cognition and especially language and affects symbolic play and directed attention in a positive manner ${ }^{8}$. At the end of the sensorimotor period, the imitating action becomes internalized, and the child acquires the ability to mimic events without the presence of the model (deferred imitation). Earlier, imitation is only an extension of action and involves only what the child already has in his repertoire and, in the case of movements, includes those that he/she can see himself/herself doing ${ }^{8}$.

In the imitation of utterances tests (T7 and T9), a reduction in the "unsatisfactory" level and an increase in the "satisfactory" level were observed. In the deferred imitation and use of symbolic schemas tests (T11 and T12), almost all children reached the "satisfactory" level in post-stimulation (Table 2). When the child becomes capable of deferred imitation and representation, the first representative gestures and symbolic schemas are observed and generally combined with the first words ${ }^{9}$. Any type of imitation performed by the child, such as body/gestural imitation, imitation of utterances or 
deferred imitation, follows a hierarchy preceding future language acquisition.

The DS child first understands facial and language expressions based on the physical context in which communication takes place ${ }^{10}$. The use of verbal language can begin in several ways, such as in words and phrases, and emerges from the communicative intentions of the speaker. In this study, it was observed that the children with DS had communicative intent, which was confirmed in the test in which the therapist presented a song and danced with the patient. When stopping the game, it was expected that the child would somehow ask for the music to continue.

It was also noted that in the expressive vocabulary: words and phrases guideline, no significant improvement was observed in the post-intervention responses compared with the initial evaluation. Note that children with DS have a greater developmental delay in this area; thus, the reduced development in the expressive part was because the eight therapeutic sessions were inadequate. Continuation of the stimulation process would be required for improvements to be observed.

Confirming the findings of Lima et al. ${ }^{11}$ and Seno et al. ${ }^{12}$, expressive oral language is typically more changed than receptive language; thus, children with DS use gestural communication in a more persistent and prolonged manner than children with typical development ${ }^{13}$.

Gestures play a predictive role in the lexical development of children with DS, and continuity of preverbal and verbal development can be observed by means of gestural production, which will have no negative influence on the emergence of oral language; in contrast, it can play the role of a "bridge" to the start of these utterances and an increase in lexicon",13,14.

Early stimulation aimed at the characteristics of children with DS, associated with the family's adherence to treatment, promotes neural plasticity mechanisms, which is important for the overall development of these children ${ }^{15}$. The continuity of speech-language stimulation is crucial to language development in children with DS, as a complex network of skills is involved in this process. Having regular stimulation can aid in the development of all necessary aspects of communication during childhood.

Therefore, some tests may not have registered responses after the eight therapy sessions included in this research; stimulation would need to continue so that these skills can be developed and substantiated, always emphasizing the quality, duration and form by/ in which the individual is stimulated. It should be noted that a limitation of this study was that speech-language stimulation was reevaluated immediately after the intervention. Therefore, new studies should be developed in which a later reevaluation of the stimulation is performed, after a longer period of time, to verify the long-term benefits of the speech-language intervention.

\section{CONCLUSIONS}

Speech-language stimulation contributes to the development of language in children with DS. This study revealed positive and immediate post-stimulation effects on the skills of gestural/body imitation, imitation of utterances, deferred imitation and the use of symbolic schema, communicative intent and receptive vocabulary of the participants.

\section{REFERENCES}

1. Ferreira-Vasques AT, Abramides DVM, Lamônica DAC. Mental age in the evaluation of the expressive vocabulary of children with Down Syndrome. Rev. CEFAC. 2017;19(2):253-9.

2. Lima ILB. Interações multimodais na clínica de linguagem: a criança com síndrome de Down. [Dissertação] João Pessoa (PB): Universidade Federal da Paraíba; 2016.

3. Lamônica DAC, Ferreira-Vasques AT. Communicative and lexical skills in children with Down syndrome: reflections for inclusion in school. Rev. CEFAC. 2015;17(5):1475-82.

4. Ferreira-Vasques AT, Lamônica DAC. Motor, linguistic, personal and social aspects of children with Down syndrome. J Appl Oral Sci. 2015;23(4):424-30.

5. Damasceno BCE, Leandro VSB, Fantacini RAF. The importance of playing for child development with Down syndrome. Res Soc Dev. 2017;4(2):142-52.

6. Silva MFMC, Kleinhans ACS. Processos cognitivos e plasticidade cerebral na Síndrome de Down. Rev Bras Educ Espec. 2006;12(1):123-38.

7. Limongi SCO, Flabiano-Almeida FC, Carvalho AMA. Plano terapêutico fonoaudiológico (PTF) para o desenvolvimento inicial de linguagem e cognição na síndrome de Down. In: Pró-Fono (Org). Planos Terapêuticos Fonoaudiológicos (PTFs). Barueri, SP: Pró-Fono; 2012. Volume 1. p. 209-16.

8. Moura MLS, Ribas AFP. Imitação e desenvolvimento inicial: evidências empíricas, explicações e 
implicações teóricas. Estudos de Psicologia. 2002;7(2):207-15.

9. Flabiano-Almeida FC, Limongi SCO. The role of gestures in oral language development of typically developing children and children with Down syndrome. Rev Soc Bras Fonoaudiol. 2010;15(3):458-64.

10. Santana CCVP, Souza WC, Feitosa MG. Recognition of facial emotional expressions and its correlation with cognitive abilities in children with Down syndrome. Psychol neurosci. 2014;7(2):73-81.

11. Lima ILB, Delgado IC, Cavalcante MCB. Language development in Down syndrome: literature analysis. Distúrb Comun. 2017;29(2):354-64.

12. Seno MP, Giacheti CM, Moretti-Ferreira D. Narrative language and fluency in Down syndrome: a review. Rev. CEFAC. 2014;16(4):1311-7.

13. Zampini L, Salvi A, D'Odorico L. Joint attention behaviours and vocabular development in children with Down syndrome. J Intellect Dis Res. 2015;59(10):891-901.

14. Bello A, Onofrio D, Caselli MC. Nouns and predicates comprehension and production in children with Down syndrome. Res Dev Disabil. 2014;35(4):761-75.

15. Medrado CS, Nunes Sobrinho FP. Evidência científica para intervenções em crianças com síndrome de Down. RECIIS. 2016;10(2):1-12. 


\section{APPENDIX A}

\section{Evaluation plan for the initial development of language and cognition in Down syndrome}

(Adapted from Limongi; Fabian-Almeida, Carvalho, 2012')

Name:

Date of birth: Date of protocol application:

The aim of this protocol is to evaluate, in the context of Down syndrome:

- Cognitive development;

- Communicative intent;

- Lexical development; and

- Ability to construct sentences.

\section{Coordination of sensorimotor schemas:}

Test 1: The therapist should offer an object to the child and encourage him/her to pick it up and handle it (e.g.: kneading, squeezing).
( ) Unsatisfactory
( ) Regular
( ) Satisfactory

Test 2: The therapist should offer objects to the child and encourage him/her to pick them up and handle them (example: hitting one against the other, putting one inside the other, stacking them).
( ) Unsatisfactory
( ) Regular
( ) Satisfactory

\section{Constitution of object permanence:}

Test 1: The therapist should hide an object of interest to the child, leaving part of it showing so that the child can find it.
( ) Unsatisfactory
( ) Regular
( ) Satisfactory

Test 2: The therapist should hide an object in his/her hand so that the child does not see it and then move it to another location (e.g.: inside a cabinet). He/She should then show the child his/her empty hand and encourage him/her to search for the object.
( ) Unsatisfactory
( ) Regular
( ) Satisfactory

\section{Gestural/body imitation:}

Test 1: The therapist should perform visible gestures to the child, maintaining eye contact, in order for him/her to perform the same gesture (example: blowing a kiss, smacking his/her lips while at the same time touching the child's lips, so that he/she has the sensation of movement required for executing the gesture).
( ) Unsatisfactory
( ) Regular
( ) Satisfactory

Test 2: The therapist should perform an action in front of the child, ensuring that he/she is paying attention (e.g.: putting the phone to his/her ear) and then offer the object to the child, suggesting that he/she mimic the action.
( ) Unsatisfactory
( ) Regular
( ) Satisfactory

\section{Imitation of utterances:}

Test 1: The therapist should associate a particular sequence of sounds to motor actions for the child to imitate (e.g.: clapping and saying "pa pa pa").
( ) Unsatisfactory
( ) Regular
( ) Satisfactory

Test 2: The therapist should associate an action with its respective verbalization (e.g.: pushing a cart and saying "beep beep" or singing to a doll and saying "nana nene" (lull-a-baby).
( ) Unsatisfactory
( ) Regular
( ) Satisfactory

Test 3: The therapist should make a sound, and then the child has to associate it with the source that produced it, with visual support (e.g.: pointing to an image of a dog saying "woof woof")- see Appendix.
( ) Unsatisfactory
( ) Regular
( ) Satisfactory 
Test 4: The therapist should make a sound, and then the child has to associate it with the source that produced it, without visual support. (e.g.: using onomatopoeia such as "meow").
( ) Unsatisfactory
( ) Regular
( ) Satisfactory

\section{Deferred imitation and use of symbolic schema:}

Test 1: The therapist should offer an object (e.g.: telephone) to see if the child performs the symbolic action for the chosen object.
( ) Unsatisfactory
( ) Regular
( ) Satisfactory

Test 2: The therapist should offer non-figurative objects so that the child represents symbolic schemas in the absence of the actual object itself, providing a model (e.g.: a block of wood that can be turned into a phone, plane, car).
( ) Unsatisfactory
( ) Regular
( ) Satisfactory

\section{Communicative intent:}

Test 1: The therapist should present a song, dancing with the child and then stop the game and wait for the child to communicate in any way that he/she wants to play again.
( ) Unsatisfactory
( ) Regular
( ) Satisfactory

Test 2: The therapist should engage the child in cooperative games (e.g.: throwing the ball to the child and asking him/her to throw it back).
( ) Unsatisfactory
( ) Regular
( ) Satisfactory

\section{Receptive vocabulary:}

Test 1: During a game, the therapist must name two objects and then ask the child to choose between the two objects (e.g.: "Now should we play with the ball" pointing to the ball, "or with the doll/push chair?" pointing to the doll/push chair).
( ) Unsatisfactory
( ) Regular
( ) Satisfactory

Test 2: The therapist should separate two or three objects and name them several times without the use of gesture. He/She should then verbally request that the child points to, or fetches them, one by one (e.g., "where is the ball?", and after the child points to it, "give me the ball" and then repeats this with the other objects, i.e., the phone and doll/push chair).
( ) Unsatisfactory
( ) Regular
( ) Satisfactory

\section{Expressive vocabulary: words and phrases.}

Test 1: The therapist must promote situations in which the child is requested to name 6 figures (see Appendix).
( ) Unsatisfactory
( ) Regular
( ) Satisfactory

Test 2: The therapist must promote situations in which the child verbalizes actions that took place and tells a short story based on the figures from the previous test (e.g.: asking the child to describe any action that he/she performed during the evaluation or tell a story).
( ) Unsatisfactory
( ) Regular
( ) Satisfactory

Test 3: The therapist must sing songs while performing contextualized gestures with the child (e.g.: happy birthday to you); after singing to him/her a few times, he/she should leave gaps to be completed by the child. (Example: ra tim... "bum").
( ) Unsatisfactory
( ) Regular
( ) Satisfactory 